\title{
0 HOLISMO FISICALISTA DE NEURATH: UMA AUTOCRÍTICA DO POSITIVISMO LÓGICO
}

\author{
Gelson Liston \\ Universidade Estadual de Londrina
}

Resumo: 0 holismo fisicalista de Neurath representa a autocrítica do positivismo lógico em um período em que o conflito era travado contra uma perspectiva de reconstrução lógica fundacionalista do conhecimento científico, sobretudo sustentada por Carnap. Neste artigo discutiremos o debate sobre sentenças protocolares ocorrido na década de trinta do século vinte no Círculo de Viena, ressaltando a perspectiva empirista de Neurath e sua influência no pensamento de Carnap rumo ao fisicalismo falibilista.

Palavras-chave: Fisicalismo, Holismo, Falibilismo, Unidade da Ciência, Positivismo Lógico.

Abstract: Neurath's physicalist holism represents an internal critique of logical positivism in a period in which the debate concerned the perspective of the logical foundational reconstruction of scientific knowledge, as supported by Carnap in particular. In this article we will discuss the debate regarding protocol sentences which occurred in the thirties of the twentieth century within the Vienna Circle, emphasizing Neurath's empiricist perspective and its influence on Carnap's thought toward fallibilist physicalism.

Keywords: Physicalism, Holism, Fallibilism, Unity of Science, Logical Positivism.

\section{1 - Introdução}

Neste artigo $^{1}$, faremos uma análise da unidade da ciência em Neurath, construída sobre uma base linguística fisicalista e conhecida como um manifesto antifundacionalista. Discutiremos a importância de Neurath no abandono, por parte de Carnap, do fenomenalismo e do fundacio-nalismo ${ }^{2}$.

\footnotetext{
1 Uma parte deste artigo foi apresentada no V Simpósio Internacional Principia, Florianópolis.

2 Sobre a controversa posição fundacionalista de Carnap, cf. LISTON, 2012.
} 
A proposta fisicalista revisionista de Neurath será discutida enquanto uma crítica ao fundacionalismo e ao solipsismo metodológico defendidos por Carnap. Avaliaremos o debate sobre as sentenças protocolares na década de 1930, evidenciando que a postura epistemológica falibilista de Neurath teve uma influência marcante em dois momentos centrais do trabalho de Carnap: o abandono do fundacionalismo e a alteração da base linguística da ciência unificada. Além disso, Neurath critica uma atitude, no mínimo suspeita, de alguns integrantes do Círculo de Viena, que propuseram uma atitude científica sem metafísica, mas que, em seus procedimentos mais básicos, defenderam uma relação entre linguagem e fatos.

\section{2 - A Crítica de Neurath ao Fenomenalismo e ao Fundacionalismo de Carnap}

Neurath procura estabelecer os fundamentos da ciência unificada por meio de uma linguagem unificada; a linguagem fisicalista:

O programa do fisicalismo nos mostra a possibilidade de construção [da ciência] sobre uma linguagem científica uniforme, com uma terminologia uniforme; isso está em perfeita harmonia com as circunstâncias que dispomos na conexão de enunciados e termos de diferentes disciplinas para a dedução de predições individuais e na conexão de enunciados de teorias com predições individuais. (NEURATH, 1936a, p. 133)

Para Neurath, um dos problemas da unificação da ciência está na utilização da linguagem: "Dependendo do grau em que as ciências têm-se desenvolvido, diferentes disciplinas têm elaborado linguagens científicas particulares, dificultando o estabelecimento de contato entre elas" (NEURATH, 1936c, p. 139). Assim, o primeiro passo a ser dado é a construção de uma linguagem unificada que possibilite a conexão de leis de áreas distintas, aumentando o poder preditivo da ciência. O fisicalismo torna possível a unificação da linguagem científica e, ao mesmo tempo, evita formulações metafísicas. Tal unificação é o principal propósito da enciclopédia da ciência unificada, que conta com a cooperação de 
especialistas de diferentes áreas que defendem o empirismo científico ${ }^{3}$. Essa tarefa deve ser executada passo a passo, sem que se abra mão, ao menos inicialmente, da linguagem ordinária. O programa da ciência unificada, por sua vez, não pretende construir um sistema único para todas as disciplinas científicas, mas possibilitar um contato maior entre seus enunciados, tornando-se o símbolo do desenvolvimento científico cooperativo.

Deste modo, a tese da unidade da ciência não implica a idéia de um sistema único. Sobre isso, Neurath afirma que o programa da ciência unificada não pretende alcançar "“um' sistema de ciência que possa tomar o lugar do 'mundo real', como se costuma falar. (...) O sistema é a grande mentira científica. (...) Multiplicidade e incerteza são essenciais” (1935a, p. 116). Tanto a idéia de um sistema único, quanto a defesa do confronto entre enunciados e fatos, assim como a defesa de enunciados básicos fundamentais, são, na concepção de Neurath, pseudo-racionalismo (cf. 1935a, p. 118).

O movimento da ciência unificada não tem por objetivo a criação de uma super-ciência, legisladora das ciências particulares, tampouco uma síntese, ou grande sistema. Na prática, a situação é mais complicada, posto que "frequentemente acontece que uma determinada teoria, útil em um determinado campo, contradiz outra teoria útil em um campo diferente" (NEURATH, 1941, p. 215). A proposta de Neurath é, a partir da unificação da linguagem da ciência, melhorar cada vez mais a relação entre as diversas ciências, departamentalizadas por razões práticas e linguisticamente unificadas por razões teóricas. Devido ao fato de que novas teorias, com novos termos ${ }^{4}$, a qualquer momento podem surgir, o trabalho de unificação torna-se uma atividade permanente (cf. NEURATH, 1937b, p. 172).

Contudo, Neurath se distancia do fenomenalismo carnapiano defendido no Aufbau, e sua tese fisicalista revisionista se apresenta como

\footnotetext{
3 "Como eu tenho mostrado, a sugestão de Mach, de uma linguagem cientíica, suplementada por Carnap e outros, forma a espinha dorsal da minha tentativa científica de fazer algo para a unificação de nosso empreendimento científico" (NEURATH, 1946a, p. 232).

4 "O jargão universal está em contínua construção, assim como nossa vida e nossas ciências" (NEURATH, 1941, p. 214). No caso de Carnap, devemos mencionar que a interpretação de uma teoria é parcial, devido ao excesso de significado dos termos teóricos que nela ocorrem. Ainda que em uma nota, podemos apresentar a visão sintática de Carnap da seguinte forma: Uma teoria científica é apresentada como sendo uma estrutura linguística que pode conter termos lógicos e termos não-lógicos. Os termos não-lógicos podem ser divididos em um conjunto de termos observáveis e um conjunto de termos teóricos, mais as regras de correspondência que funcionam (por analogia) como um dicionário na relação entre os termos teóricos e os termos observacionais. A interpretação dos termos teóricos é parcial porque tais termos não são explicitamente definidos. Assim, com o avanço da ciência, não apenas novos termos podem ser introduzidos, como também novas regras de correspondência.
} 
uma crítica ao fundacionalismo reducionista e ao solipsismo metodológico defendidos por Carnap:

Carnap, na tentativa de criar um sistema construcional, fez uma distinção entre duas linguagens: uma 'solipsista' (fenomenológica) e uma 'intersubjetiva' (fisicalista). Ele tentou deduzir o fisicalismo a partir do fenomenalismo. Contudo, em minha opinião, pode ser mostrado que esta divisão não pode ser levada adiante, mas, ao contrário, apenas uma linguagem em questão deve ser considerada desde o início, e esta é a linguagem da física. (NEURATH,1931b, p. 54).

No período fundacionalista, Carnap compara a ciência a um edifício construído sobre bases sólidas (não inabaláveis). Neurath, por sua vez, compara a ciência a um barco em contínua reconstrução. $\mathrm{Na}$ concepção de Neurath, não é possível reconstruir o conhecimento sobre a base de sentenças simples e irrevisáveis, tampouco é defensável a idéia de primazia epistêmica, pois uma sentença qualquer só pode ser avaliada se estiver integrada a um sistema.

A posição de Neurath, posteriormente aceita por Carnap, é de que a linguagem da ciência unificada, devido ao progresso do conhecimento, se apresenta numa situação de contínuo desenvolvimento:

Aquele que deseja criar uma visão de mundo, ou um sistema científico, deve operar com premissas questionáveis. Cada tentativa de criar uma visão de mundo a partir de uma tabula rasa e de uma série de enunciados que são reconhecidos como definitivamente verdadeiros é, necessariamente, um grande equívoco. Os fenômenos encontrados estão interconectados de tal modo que nunca podem ser descritos por meio de uma cadeia unidimensional de enunciados. A correção de cada enunciado está relacionada a todos os demais. É absolutamente impossível formular um enunciado singular sobre o mundo, sem, ao mesmo tempo, fazer o uso tácito de inúmeros outros. Também não podemos expressar qualquer enunciado sem aplicar todos os nossos conceitos previamente formados. (NEURATH, 1913, p. 3).

O importante é que a linguagem, na qual a ciência unificada é expressa, permita fazer predições sobre qualquer tipo de evento que ocorre na natureza, sem, contudo, ter de ser reduzida a algum tipo de nível de objetos, por exemplo, 
a objetos autopsicológicos ou físicos, como é o caso do sistema construcional fenomenalista de Carnap. Apenas as predições devem ser redutíveis a enunciados de observação. Para Neurath, toda sentença observacional tem uma referência espaço-temporal e está sujeita a revisão. Com isso, podemos afirmar que Neurath antecipa a crítica de Quine ao dogma reducionista do empirismo - sobre a redutibilidade do sistema carnapiano às sentenças protocolares, à teoria verificacionista do significado e à idéia de primazia epistêmica. Para Neurath, qualquer investigação empírica enfrenta o caos e a ordem. $O$ objetivo é estabelecer algum tipo de ordem, mas não somente de fora, a partir de princípios a priori (lógica da ciência), tampouco a partir de um conjunto de enunciados com status epistemológico privilegiado. Diante da multiplicidade de possibilidades teóricas, as decisões práticas são fundamentais, e elas não podem ser justificadas apenas por razões lógicas. A racionalidade científica, se houver, deve ser demonstrada pela própria prática científica. Contamos com o conhecimento passado como instrumento de investigação, dependente de condições históricas e sociais (cf. NEURATH, 1930, p. 46). Deste modo, o holismo fisicalista de Neurath representa a autocrítica do positivismo lógico, um conflito travado contra uma perspectiva de reconstrução lógica fundacionalista do conhecimento científico.

Se a unidade fisicalista for alcançada de forma bem sucedida, então podemos afirmar que encontramos correlações funcionais entre leis e fenômenos em estruturas no espaço e no tempo. Criar condições para a unificação da ciência, com todas as suas leis, é a tarefa da concepção científica do mundo. Por esse motivo, Neurath chama de unidade fisicalista da ciência (cf. NEURATH, 1931a, p. 49 e 1931c, p. 325). Assim sendo, o fisicalismo de Neurath não mantém a tese reducionista de que todos os enunciados científicos podem ser reduzidos (traduzidos) em enunciados fisicalistas, mas que tais enunciados permitem um controle espaço-temporal sistemático através da observação e de articulações lógicas.

$\mathrm{O}$ modo pelo qual Neurath pensa a unidade linguística da ciência unificada sem reducionismo é sustentado pela idéia de que não é necessária, e tampouco possível, a redução dos sistemas de leis a uma única linguagem tida como ideal, no caso, a linguagem fisicalista, mas que essa linguagem sirva para fazer predições sobre qualquer evento (científico) da natureza. Assim, a linguagem fisicalista da ciência unificada não está divorciada da linguagem ordinária. Não podemos contar com uma linguagem ideal, mas trabalhar na 'purificação' da linguagem ordinária, eliminando gradualmente os componentes metafísicos, mesmo sabendo que "conglomerações linguísticas vagas sempre permanecem de um modo ou de outro como componentes do barco". Também podemos entender a metáfora náutica de 
Neurath como uma crítica à idéia de conhecimento científico enquanto sistema ideal, completo e auto-suficiente (cf. 1959a, p. 201).

A criação de um jargão universal [universal slang] é uma das tarefas da ciência unificada, e nisso Neurath reconhece o valor do trabalho de Carnap na construção da sintaxe lógica da linguagem, mas defende que a linguagem unificada deva acompanhar o constante desenvolvimento da ciência, sendo, portanto, não apenas sintática, mas também pragmática, ou seja, devido ao seu caráter histórico, a linguagem está sujeita a mudanças. Deste modo, os enunciados protocolares, no que se refere à possibilidade de revisão, estão na mesma situação dos demais enunciados científicos. Os enunciados protocolares possuem grande estabilidade, mas são sempre passíveis de revisão. Quanto à análise lógica, devemos reconhecer o seu valor na construção de um framework mais consistente para as ciências. Esta parece ser a mensagem de Neurath em sua famosa metáfora do barco e evidencia sua oposição à postura de Carnap em relação aos enunciados protocolares que, segundo este, não requerem verificação, isso já em sua fase fisicalista de $1932 .{ }^{5}$

A tarefa da ciência unificada é estabelecer correlações entre as leis de diversas áreas a fim de alcançar predições bem sucedidas. Quanto mais bem sucedido for o estabelecimento destas correlações, maior será a capacidade preditiva da ciência. Isto é o que justifica, na prática, o interesse na ciência unificada. Certamente, diz Neurath (1931d, p. 66), "as leis podem ser diferenciadas umas das outras: por exemplo, leis químicas, biológicas ou sociológicas. Entretanto, não se pode afirmar que uma predição de um processo individual concreto depende apenas de um tipo definido de leis".

Assim, uma das tarefas da concepção científica do mundo, além da eliminação gradual dos elementos metafísicos, é criar condições favoráveis para a efetivação de um sistema fisicalista unificador. De acordo com essa concepção, Neurath tenta mostrar que a eliminação da metafísica não se dá por uma questão de significado, mas como resultado de uma decisão: a decisão de aceitar a tese fisicalista - a tese da unidade da ciência (cf. CIRERA, 1994, p. 119).

\section{3 - Coerentismo e Empirismo}

Neurath entende que a ciência unificada deva ser construída em um sistema consistente de protocolos e leis. Esta é a posição coerentista que Neurath assume para seu sistema, de modo que a verdade, ou falsidade de uma sentença se torne apenas uma questão de expediente:

\footnotetext{
5 Nos referimos ao livro The Unity of Science. Essa posição, contudo, é abandonada a partir de 1934: The Logical Syntax of Language.
} 


\begin{abstract}
$\mathrm{Na}$ ciência unificada, tentamos construir um sistema nãocontraditório de sentenças protocolares e não-protocolares (inclusive as leis). Quando uma nova sentença nos é apresentada, nós a comparamos com o sistema de que dispomos, e determinamos se ela entra ou não em conflito com este sistema. Se a sentença conflitar com o sistema, podemos rejeitá-la como desnecessária (ou falsa) (...). Por outro lado, alguém pode aceitá-la e mudar o sistema de modo que este permaneça consistente após sua inclusão. A sentença pode então ser chamada "verdadeira". (NEURATH, 1959a, p. 203).
\end{abstract}

Entretanto, a decisão de aceitar o novo enunciado, rejeitando o sistema, é mais difícil e não pode ser tomada sem uma certa hesitação. Mas "não há outro conceito de 'verdade' para a ciência”. "A definição 'correto' e 'incorreto' aqui proposta, abandona a definição usualmente aceita no Círculo de Viena que recorre a 'significado' e 'verificação”' (NEURATH, 1931d, p. 66).

Oberdan (1996, p. 269) apresenta o fisicalismo como uma oposição oficial de Neurath, Carnap e Hempel à epistemologia fundacionalista e à teoria correspondentista da verdade do Círculo de Viena (Schlick, Waismann, Wittgenstein). Assim, o fisicalismo propõe o falibilismo e este se apresenta como uma concepção oposta ao fundacionalismo e ao correspondentismo. Sobre isso, dois comentários devem ser feitos no que diz respeito à posição de Carnap: a) A posição fisicalista inicial (1932) é fundacionalista. Além disso, o fisicalismo é uma possibilidade alternativa do sistema construcional desenvolvido no Aufbau; b) O correspondentismo nunca foi abandonado.

Se com Neurath podemos afirmar que nenhuma sentença dispõe de uma posição definitiva na ciência unificada, também podemos, de igual modo, afirmar que qualquer sentença pode ser acomodada a algum sistema da ciência unificada. Esse sistema, assim como uma máquina, para lembrarmos de outra metáfora de Neurath, pode ser reconstruído e cientificamente justificado. ${ }^{6}$ Tais sentenças são comparadas entre si em um sistema previamente aceito, e afirmar que uma nova sentença é correta significa dizer que tal sentença pode ser incorporada na totalidade desse sistema sem gerar conflito (cf. 1959b, p. 291). Todavia, temos aqui uma posição de Neurath que nos parece intrigante por sugerir que a ciência unificada estaria fundamentada numa teoria coerentista em que a verdade

\footnotetext{
${ }^{6}$ A justificação de um sistema científico é dada pela ausência de contradição deste com as sentenças de observação (protocolos). Não obstante, tal sistema tem de ser preditivamente útil. Disso se segue a grande importância que Neurath atribuía às leis.
} 
confunde-se com a aceitabilidade de um determinado sistema, tornando difícil a defesa do próprio empirismo.

Entretanto, a posição de Neurath pode ser vista como uma autocrítica ao empirismo, pois a relação entre enunciados e fatos implica uma concepção metafísica, embora a teoria correspondentista não implique, necessariamente, esse tipo de relação, pois, quando Carnap se refere ao conteúdo objetivo das sentenças sintéticas, enfatizando seu caráter nãoconvencional, e menciona a importância da primeira operação no teste de enunciados sintéticos, ele fala da confrontação entre enunciados e observações factuais (cf. 1963b, p. 864).

Neurath expressa sua crítica do seguinte modo:

\begin{abstract}
Enunciados são comparados com enunciados, não com 'experiências', nem com o 'mundo', nem com qualquer outra coisa. Todas essas duplicações sem sentido pertencem, mais ou menos, a uma metafísica refinada e, portanto, devem ser rejeitadas. Cada novo enunciado é confrontado com a totalidade dos enunciados existentes que, até o momento, estão harmonizados uns com os outros. Um enunciado é chamado correto, se ele puder ser incorporado nesta totalidade. Se não puder ser incorporado, é rejeitado como incorreto. (NEURATH, 1931d, p. 66).
\end{abstract}

A concepção anticorrespondentista de Neurath nos deixa uma outra questão: Que razões teríamos para revisar um sistema e então aceitar uma nova sentença como verdadeira ou correta? As razões parecem ser apenas de ordem pragmática ou instrumental: aumentar o poder preditivo do sistema. Assim, o objetivo é alcançar um sistema autoconsistente que seja um instrumento para fazer predições bem sucedidas (cf. 1959b, p. 286). Portanto, o coerentismo não é apenas consistência interna (lógica), mas também capacidade preditiva (empírica).

O que, de fato, resta de problemático é o critério a ser utilizado para a escolha de um determinado sistema ou, ainda, de uma determinada sentença, que não seja circular, ou em outros termos, utilizar a noção de verdade (correção) para definir a coerência, e a noção de coerência para definir a de verdade. O que nos parece é que algum tipo de recurso externo (correspondência) tem de ser admitido. Esse problema surge não pelo fato de Neurath ser um coerentista, mas por defender uma posição anticorrespondentista. Em nossa análise, uma posição não exclui, 
necessariamente, a outra. Podemos, por exemplo, afirmar, sem problemas, que Carnap defende o correspondentismo, sem ser um anticoerentista. ${ }^{7}$

O ponto interessante desse raciocínio é a crítica de Neurath ao atomismo lógico $^{8}$ e à idéia de uma linguagem ideal que, de certa forma, está relacionada com a teoria correspondentista. Além disso, não podemos testar uma sentença isoladamente, porquanto que não é possível confrontar uma sentença com algum fato. Isso se deve basicamente à complexidade dos fenômenos e à dependência teórica da experiência. Todavia, não se resolve tal problema afirmando que a verdade de uma sentença depende da verdade (consistência) das demais, em um sistema organizado.

Ao comentar os trabalhos de Neurath, Uebel vê neles uma antecipação da epistemologia naturalizada muito mais do que uma forma de coerentismo (relacionado, principalmente, com a metáfora do barco). A posição de Uebel (1992, p. 304) é que Neurath rejeita a teoria correspondentista da verdade; mas, ao invés de propor uma teoria alternativa da verdade, ele teria encaminhado o debate para uma teoria da aceitação. Todavia, como Neurath identifica a aceitação de um sistema, ou de um enunciado, a partir da noção de verdade como ausência de contradição, então não vemos problemas em identificar a aceitação com a coerência. ${ }^{9}$ Contudo, precisamos nos posicionar sobre a teoria coerentista de Neurath a fim de saber se esta é uma teoria definicional ou criterial da verdade para, então, podermos manter a posição de que o coerentismo de Neurath é, sim, uma teoria da verdade, uma teoria alternativa do correspondentismo.

Uma definição de verdade apresenta o significado do termo 'verdadeiro'. Um critério de verdade apresenta um teste por meio do qual podemos afirmar se um enunciado é 'verdadeiro' ou 'falso'. A questão que nos preocupa neste momento é saber se a teoria coerentista de Neurath é criterial ou definicional. Como Neurath faz referência à aceitação ou rejeição de um enunciado tendo como referência (também poderíamos dizer teste) a consistência ${ }^{10}$ deste com

7 De certo modo, tal posição parece trivial. Podemos defender a visão correspondentista e aceitar que apenas as sentenças fundamentais precisam estar em correspondência com os assim chamados 'estados de coisa', enquanto que as outras precisam ser coerentes com as fundamentais. Por outro lado, isso pode não ser trivial, e essa parece ser a posição de Neurath, pois se o coerentismo for lido em seu sentido mais forte, então ele certamente colide com o correspondentismo.

8 Estamos nos referindo à ideia de uma congruência estrutural entre proposição e fato.

9 Não estamos, é claro, afirmando que a aceitação de uma teoria implica a crença em sua verdade. Podemos, por exemplo, aceitar uma teoria por conta de sua adequação empírica.

${ }_{10}$ Como veremos mais adiante, além da consistência, uma teoria científica deve contar com a amplitude ou abrangência. Além disso, a aceitação de um novo enunciado ou a revisão do sistema precisa, de alguma forma, de uma justificação mais robusta, que vá além da simples consistência. Neurath 
um sistema previamente aceito, estamos inclinados a afirmar que seu coerentismo é criterial, já que a relação entre enunciados é um teste que incide na aceitação ou rejeição de enunciados, ou do próprio sistema.

Dessa forma, estaria Neurath se distanciando da epistemologia enquanto justificação das cognições, ou propondo uma alternativa ao fundacionalismo carnapiano, afirmando que os enunciados protocolares são falíveis como quaisquer outros enunciados científicos e que, portanto, a coerência do sistema torna-se a base de escolha para a aceitação ou não de novos enunciados? Esta, por exemplo, é a posição de Schlick (1934, p. 69), que, ao discutir a questão do critério de verdade como o problema do fundamento de todo o conhecimento, reconhece (e critica) em Neurath a teoria coerentista da verdade.

A posição de Schlick é contrária à posição de Neurath em relação aos sistemas sintéticos que, segundo ele, além da coerência interna, necessitam da "coerência com afirmações bem específicas e especiais", pois "quem toma a sério a coerência como único critério da verdade, deve considerar as lendas poéticas tão verdadeiras quanto um relato histórico ou as proposições de um manual de química"11 (1934, p. 70-1). Contudo, a crítica de Neurath à teoria correspondentista aponta para o fato de que não apenas essa relação entre linguagem e mundo não é possível, assim como o conhecimento não pode ter como base percepções subjetivas, ou uma linguagem fenomenológica. Segundo Rutte (1991, p. 176), Neurath duvida da possibilidade de um conhecimento imediato, pois "ele dá a impressão de pensar que o conhecimento sempre tem o caráter de enunciados, e enunciados nunca são imediatos, mas implicam hipóteses e teorias de todo o tipo. Percepções não podem servir como uma ponte para esta comparação". De acordo com essa posição, não há observação neutra ${ }^{12}$, ou seja, todas as sentenças de observação estão teoricamente contaminadas.

Conquanto Schlick aceite que todas as proposições da ciência não passam de hipóteses com relação ao valor de verdade, de modo que o fundamento inabalável do conhecimento não pode ser afirmado, ele reconhece a necessidade de pontos de referência, dados pelas constatações (afirmações empíricas), a partir dos quais o conhecimento é estruturado e confrontado. São as constatações, observações privadas, imediatas e, portanto,

apresenta uma importante razão que justificaria qualquer uma das opções: aumentar o poder preditivo do sistema.

${ }^{11} \mathrm{~A}$ crítica de Schlick será examinada nas páginas seguintes, onde apresentaremos a função da relação inferencial do coerentismo de Neurath.

${ }^{12}$ Sobre a inexistência do 'empirismo ingênuo' no positivismo lógico, ver FRIEDMAN, 1992, p. 86. 
estritamente irrevisáveis, que possibilitam o contato, por assim dizer, entre proposições e realidade, sendo, desse modo, as únicas proposições sintéticas que não são hipóteses por não fazerem parte do sistema científico de linguagem, ocupando, portanto, algum tipo de status privilegiado.

Schlick defende a possibilidade de comparar proposições com fatos (entidades não-linguísticas) em seu conhecido exemplo da catedral; para comparar o enunciado 'Esta catedral tem duas torres' com a 'realidade', basta olhar para a catedral. Segundo Schlick, essa comparação é suficiente para o convencimento de que o enunciado é verdadeiro ou falso e que não há nem um envolvimento metafísico nesse processo de conhecimento. Portanto, Schlick aceita a crítica, mas se defende do comprometimento metafísico: "eu tenho comparado proposições com fatos; desse modo, não tenho nenhuma razão para afirmar que isso não possa ser feito". Schlick apresenta o exemplo da catedral e conclui: "certamente, você não pode afirmar que este é um processo impossível e que há uma detestável metafísica nele envolvida” ("Facts and Proposition" [1935], in Philosophical Papers, vol. 2. p. 400, in COFFA, 1995, p. 369). Para Schlick, essa posição representa uma forma de assegurar a função da experiência no conhecimento científico, enquanto que o coerentismo de Neurath representa o abandono do empirismo e a relativização do conceito de verdade.

Mesmo que problemática e aparentemente contraditória, a posição de Schlick sobre a relação entre enunciados e fatos tem uma importância fundamental nessa discussão por evidenciar a função da experiência na aceitação de enunciados científicos, pois não apenas Neurath, mas também Carnap, em sua fase sintática, não discutem claramente esta questão. No caso de Carnap, trata-se da identificação da filosofia da ciência com a sintaxe lógica e da distinção entre o modo material e o modo formal de falar. ${ }^{13}$ No modo formal de falar, que é o mais correto, a 'verdade' é sintática, não semântica. Posteriormente ele reconhece esta limitação e inclui a pragmática e a semântica, possibilitando uma melhor análise dos conceitos 'verdade' e 'confirmação'.

Outro autor que podemos citar é Karl Popper, que vê na teoria coerentista de Neurath um falibilismo holístico sem limites, representando, portanto, um perigo para o empirismo. Popper, defensor do falseacionismo metodológico, restringe o convencionalismo apenas à base empírica, e não ao sistema teórico como um todo:

${ }^{13} \mathrm{Cf}$. CARNAP, The Unity of Science (1932) e The Logical Syntax of Language (1934). 
A doutrina de Neurath, de acordo com a qual as sentenças protocolares não são invioláveis, corresponde, a meu ver, a notável avanço. Contudo, desconsidera a substituição das percepções por enunciados-percepção, - mera tradução para o modo formal de expressão - a doutrina de que as sentenças protocolares admitem revisão é seu único progresso relativamente à teoria (de Fries) acerca da imediatidade do conhecimento perceptivo. ${ }^{14}$ Trata-se de um passo na direção certa; mas que a nada conduz, se não for acompanhado de outro passo: faz-se necessário um conjunto de regras para limitar a arbitrariedade na "rejeição" (ou "aceitação") de uma sentença protocolar. Neurath não nos apresenta essas regras e, assim, involuntariamente, compromete o empirismo (POPPER, 1972, p. 103-4).

A crítica de Popper à falta de limites do convencionalismo esclarece a diferença de sua posição convencionalista em relação à posição holística de Neurath, mas não deixa de ser problemática do ponto de vista puramente lógico, pois a base de teste de uma teoria é convencional e, portanto, são as convenções que decidem a escolha entre sistemas teóricos. Além disso, devemos mencionar a importância que Neurath atribui ao sucesso preditivo $^{15}$, de modo que seu convencionalismo é limitado pela prática científica, e não por uma atitude irresponsável e arbitrária da consistência pela consistência. O objetivo pragmático da investigação científica exige que um sistema (empírico), além de ser consistente, tem de ser um instrumento de predições bem sucedidas (relação inferencial do coerentismo), e estas predições podem então ser testadas por outros enunciados de observação (cf. NEURATH, 1931b, p. 53 e 1935b, p. 116-117).

Em sua resposta, Neurath (1934) reafirma a posição falibilista de que todos os enunciados empíricos são selecionados convencionalmente e que, em princípio, podem ser alterados. Aceitar isso não implica um relativismo

\footnotetext{
14 Não podemos deixar de mencionar, neste momento, que a identificação que Popper faz das sentenças protocolares de Neurath e Carnap com o chamado psicologismo da base empírica - "a doutrina de acordo com a qual enunciados podem encontrar justificação não apenas em enunciados, mas também na experiência perceptiva" (POPPER, 1972, p. 100) - é um equívoco no que se refere à concepção de Neurath (nota nossa).

15 "Na estrutura da ciência unificada, todos os tipos de classificações de enunciados são possíveis. Decidimos, por exemplo, se certos enunciados são 'enunciados de realidade', 'enunciados de alucinações', ou 'mentiras', de acordo com o grau com que estes enunciados podem ser utilizados para deduzir conclusões acerca de eventos físicos além do simples movimento labial" (NEURATH, 1931d, p. 66).
} 
radical, como afirmam Russell (1995, p. 148) e Schlick (1934, p. 71), nem o abandono do empirismo, seguindo a crítica de Popper. Simplesmente não podemos identificar decisões metodológicas com decisões arbitrárias. Se aceitarmos tal identificação em Neurath, então todo o projeto de unificação da ciência está comprometido. Sobre a falta de um critério empírico de decisão entre sistemas de enunciados, Neurath afirma que Schlick não deu a devida atenção aos enunciados protocolares fisicalistas, com localização espaço-temporal, e a função destes enquanto 'enunciados de controle' (os enunciados protocolares funcionam como enunciados de teste para um determinado sistema (cf. NEURATH, 1935b, p. 123) e são enunciados de grande estabilidade (cf. NEURATH, 1936e, p. 164). Sobre tais enunciados, Neurath (1936d, p. 151) afirma: "Aumentamos a estabilidade de nossos enunciados de controle, quando, em última instância, nos referimos a "enunciados de observação"”.

A questão é que Schlick não aceita a proposta de confrontar enunciados com enunciados ${ }^{16}$ (ademais, as constatações são enunciados de observação sacrossantos. Mas, é possível, na ciência empírica, estabelecer a verdade objetiva de algum enunciado científico, sem a referência de uma estrutura linguística?). O mesmo vale para a crítica de Russell de que a proposta de Neurath significaria o completo abandono do empirismo, uma vez que a verdade poderia ser determinada pela polícia:

Afirmar: "A é um fato empírico" é, de acordo com Neurath e Hempel, dizer: "a proposição 'A ocorre' é consistente com um certo conjunto de proposições aceitas". Em um círculo cultural diferente, outro conjunto de proposições pode ser aceito; devido a este fato, Neurath está exilado. Ele percebe que a vida prática logo será reduzida a ambiguidades, e que nós podemos ser influenciados pela opinião de nossos vizinhos. Em outros termos, verdades empíricas podem ser determinadas pela polícia. Esta doutrina, de forma evidente, representa o completo abandono do empirismo (RUSSELL, 1995, p. 148).

Para Russell, enunciados protocolares (proposições básicas) "são subclasses de premissas epistemológicas, causadas, tão imediatamente quanto possível, por experiências perceptivas” (RUSSELL, 1995, p. 137). Tais

16 Já Carnap, segundo Neurath (1934, p. 108), defende, em sua fase antifundacionalista, a função sintática dos enunciados protocolares (cf. CARNAP, 1934, p. 317ss). 
enunciados são conhecidos, independentemente de qualquer inferência feita a partir de outros enunciados.

Esses enunciados, e aqui se localiza o ponto de desacordo com a posição holista falibilista de Neurath, encontram na percepção imediata a evidência de que são verdadeiros. Além disso, para Russell, não há como construir conhecimento empírico a partir de uma construção linguística auto-suficiente, discordando, portanto, da tese central de Neurath segundo a qual 'enunciados são comparados com enunciados, não com a experiência'. $\mathrm{Na}$ tentativa de evitar uma metafísica perniciosa, a teoria de Neurath torna-se ultra-empírica (RUSSELL, 1995, p. 149).

Em outro artigo (1936d), Neurath novamente critica as posições de Schlick e Popper ${ }^{17}$, e o mesmo vale para Russell: "Nunca podemos afirmar que certas fórmulas são 'inabaláveis', 'definitivamente livres de contradições', 'absolutamente verdadeiras', nem que são 'aproximações' gradativas, como se houvesse algo determinado ou determinável” (NEURATH, 1936d, p. 145).

\section{4-Conclusão}

A discussão sobre protocolos e definição de verdade na década de 30 representa a disputa entre a epistemologia falibilista de Neurath e Carnap ${ }^{18}$ e a epistemologia fundacionalista de Schlick. No caso de Carnap, é importante notar a influência da análise metalinguística, que transforma os problemas filosóficos em questões de linguagem e, no caso das sentenças básicas, em questões sintáticas. Na visão de Neurath, o que há de mais importante são as leis e a utilização que fazemos delas para predições de eventos. Deste modo, num sistema consistente, assim concebido, todas as leis podem, sob certas circunstâncias, manter relações entre si, possibilitando predições bem sucedidas. É esta correlação de um sistema unificado de leis com eventos físicos que define o fisicalismo (cf. 1959b, p. 286). Assim, os diferentes ramos da ciência compartilham de um mesmo método, de observação e experimento, sem um acesso epistemológico privilegiado.

Se algo pode ser expresso em uma estrutura espaço-temporal, então há a possibilidade de predição e controle científico. Essa é a idéia de uma

\footnotetext{
17 Seguindo Popper, Lakatos (1979, p. 138) afirma: "a metodologia permissiva de Neurath (ou melhor, sua falta de metodologia) tornaria a ciência não-empírica e, portanto, irracional: "precisamos de um conjunto de regras para limitar a arbitrariedade de suprimir (ou aceitar) uma sentença protocolar. Neurath deixa de dar essas regras e, assim, inadevertidamente, atira o empirismo pela janela. Todo sistema torna-se defensável se for permitido simplesmente 'suprimir' uma sentença protocolar por ser inconveniente"'.

18 No caso de Carnap, a partir de 1934.
} 
concepção científica do mundo. É dessa forma, segundo Neurath, que devemos entender não só as ciências naturais, mas também as ciências humanas. Assim, podemos integrar os vários ramos da ciência, sem o ideal de uma unificação por redução e sem o abandono do empirismo. Neurath defende a unidade da ciência enquanto um trabalho cooperativo que se desenvolve gradualmente, aumentando a integração ${ }^{19}$ na busca de melhores resultados para a ciência e, consequentemente, para a vida. $\mathrm{O}$ que possibilita a integração entre as ciências (disciplinas) é o uso de uma linguagem científica unificada (a linguagem da física).

Dessa forma, Neurath afirma a importância da unificação da ciência enquanto uma atitude científica universal capaz de reunir diversas áreas do conhecimento científico a partir de uma posição empírica, com o auxílio formal da análise lógica da linguagem científica. Essa atitude, que envolve conteúdo empírico e conexões lógicas consistentes, promovendo a integração das ciências, é o objetivo da ciência unificada. As dificuldades de análise conceitual que incluem diferentes ramos da ciência, ou mesmo as existentes no interior de uma determinada ciência, serão superadas pela unificação da linguagem científica, base da ciência unificada. Ainda que dificuldades dessa natureza sempre apareçam, o importante é manter uma atitude científica crítica, mas tolerante; pois, afirma Neurath: "Questões abertas e incompletas surgem em todas as partes deste trabalho, mas o enciclopedismo mantém, todavia, que a integração das ciências é uma parte inevitável da atividade científica humana" (NEURATH, 1938, p. 23). As dificuldades que surgem devido a um número cada vez maior de especializações em determinados ramos da atividade científica podem ser minimizadas e, de certa forma, superadas, sem, contudo, a exigência de uma tradução radical, difícil e desnecessária, pois a base linguística é fisicalista, e esta, por sua vez, é suficiente para promover a integração do conhecimento científico.

Em Carnap, a preocupação com relação aos problemas da ciência empírica, a sua linguagem e a sua unidade, está relacionada com os objetivos da ciência unificada, ou seja, com a análise lógico-linguística dos enunciados e com suas relações no sentido de alcançar um sistema ordenado do conhecimento científico, mas de um modo um pouco diferente do de Neurath. A unidade torna-se um problema lógico por tratar das relações que

\footnotetext{
${ }^{19}$ Este era um dos objetivos da Enciclopédia Internacional da Ciência Unificada. "Se alguém fala de uma 'concepção' científica do mundo, em contradição a uma 'visão' filosófica do mundo, 'mundo' não está indicando um todo definido, mas um contínuo desenvolvimento na esfera da ciência. Esta concepção é deduzida a partir do trabalho científico individual, com o desejo de ser incorporado à ciência unificada. Isso é diferente na filosofia tradicional, que alcança suas conclusões sobre o 'mundo' a partir de considerações fundamentais" (NEURATH, 1930, p. 32).
} 
podemos estabelecer entre os enunciados e as leis de diversos ramos da ciência. Mas também é metodológica, pois o fisicalismo, para Carnap, é a proposta de um critério de significado científico baseado na confirmabilidade intersubjetiva - na unidade metodológica. O tipo de análise que Carnap propõe é a redutibilidade linguística (que deve ser vista como um programa de pesquisa a ser desenvolvido), tendo como base a linguagem fisicalista, segundo a qual é possível estabelecer métodos observacionais (diretos ou indiretos) de significado, através do conhecimento de critérios empíricos de aplicação aos conceitos. Como esta base, segundo Carnap, é suficiente, temos a tese forte do fisicalismo.

De acordo com Feigl (1963, p. 217), esta tese do fisicalismo representa uma nova formulação do princípio do empirismo em Carnap, superando a redução fenomenalista do Aufbau e a redução fisicalista radical da "Unidade da Ciência”. Em nossa interpretação, a liberalização do empirismo representa a unidade metodológica da obra carnapiana na busca de uma formulação cientificamente adequada. Ao analisar o artigo de Feigl, especificamente sobre a nova formulação do "princípio empirista", fundamentado em uma linguagem fisicalista, Carnap afirma ser "possível e conveniente, por razões práticas, iniciar a construção da linguagem com predicados primitivos designando propriedades dos objetos que são intersubjetivamente observáveis". Mas enfatiza "a diferença entre os dois tipos de propriedades (subjetivamente observável e intersubjetivamente confirmável) não é uma questão de princípio, mas meramente de grau". Carnap sustenta: "tudo o que é subjetivamente confirmável é, também, intersubjetivamente confirmável”; em outros termos, "a privacidade do conhecimento não é absoluta, mas apenas uma questão de grau” (CARNAP, 1963b, p. 882-883). A própria alteração da base empírica e do critério de significado é "uma questão de modificação, não de uma total rejeição deste requisito” (CARNAP, 1936-7, p. 422). Deste modo, a alteração deve ser vista como a proposta de uma nova forma de linguagem (um modo de falar), mais eficiente, e não como uma ruptura.

A unidade que Carnap propõe é a unidade dos termos, conceitos ou objetos: um sistema que permite construir ou reduzir objetos de diferentes níveis. Todavia, uma questão importante, ou um problema, como afirma Carnap, é a unidade (consistente) das leis, pois o tratamento tem de ser diferente do tratamento dado aos termos:

A relação entre os termos dos vários ramos da ciência tem sido considerada. Permanece a tarefa de analisar a relação entre as leis. De acordo com nossas considerações prévias, uma lei 
biológica contém apenas termos que são redutíveis a termos físicos. Conseqüentemente, há uma linguagem comum à qual ambas as leis, biológicas e físicas, pertencem, de modo que possam ser logicamente comparadas e conectadas. Podemos questionar se, ou não, uma certa lei biológica é, ou não, compatível com o sistema de leis físicas e se é, ou não, derivável destas. Mas a resposta a esta questão não pode ser inferida a partir da redutibilidade dos termos. No estado atual de desenvolvimento da ciência, certamente não é possível derivar as leis biológicas a partir da física (CARNAP, 1938, p. 60).

Esta citação deixa clara a posição de Carnap em relação ao tipo de unidade pretendida para a ciência. Embora não haja uma impossibilidade de princípio para a construção da unidade da ciência por meio da unidade das leis, "a construção de um sistema homogêneo de leis para a ciência como um todo é um objetivo para o futuro desenvolvimento da ciência” (1938, p. 61). Portanto, a unidade da ciência é uma unidade conceitual, e não nomológica. No entanto, Carnap defende uma relação funcional das leis, pois as predições feitas a partir de determinada lei, de determinado ramo da ciência, quase sempre envolvem o conhecimento de leis de outros ramos, e a aplicação prática do conhecimento teórico depende da unidade linguística.

A dificuldade de Carnap em relação à unidade das leis deve-se ao fato de que o método utilizado por ele para explicar a unidade da ciência é reducionista: os termos (conceitos) contidos em enunciados de um tipo mais elevado podem ser traduzidos ou definidos a partir de um vocabulário mais básico da física. A aplicação desse método às leis (reducionismo de leis) implicaria a possibilidade de explicar, ou substituir leis de um nível mais elevado a partir de leis de um nível inferior e, finalmente a leis da física. A dificuldade aqui envolvida implica a possibilidade de reduzir o universo de discurso de uma lei $x$ ao universo de discurso de uma lei $y$, sendo que $x$ e $y$ pertencem a diferentes ramos e não se referem aos mesmos objetos, ainda que isso nem sempre seja o caso, pois pode haver a redução de leis pertencentes ao mesmo ramo, apenas com especificidades distintas, como é o caso das inúmeras especialidades existentes em um mesmo ramo da ciência.

O reducionismo linguístico proposto por Carnap, enquanto método para o programa da unidade da ciência privilegia os conceitos observacionais, de tal forma que os conceitos teóricos são interpretados ${ }^{20}$ a partir de

20 Trata-se da incompletude de interpretação dos termos teóricos. Eles recebem apenas uma interpretação parcial quando em relação com termos observacionais. 
condições técnicas apropriadas que possam indicar a presença destes num sistema linguístico. Esse método, de acordo com Carnap, possibilita reconstruir racionalmente a linguagem da ciência.

Por fim, reconhecemos aqui a importância da oposição de Neurath em relação ao irracionalismo e a qualquer movimento intelectual anticientífico. Essa atitude de Neurath foi, certamente, uma das principais razões para a notoriedade que o Círculo de Viena alcançou na década de trinta. As posições de Carnap e de Neurath são diferentes, mas apontam para a eliminação das intermináveis disputas metafísicas, quase sempre oriundas de confusões linguísticas. $\mathrm{Na}$ solução de tais problemas, encontramos também a motivação de Carnap em seu movimento de abandono da epistemologia, que mistura elementos lógicos e psicológicos ( $A u f b a u)$, rumo à lógica da ciência e à ampla aplicação do princípio de tolerância linguística (Logical Syntax of Language) em um "oceano aberto de possibilidades ilimitadas" (Cf. CARNAP, 1934, p. xv).

\section{Referências Bibliográficas}

AYER, A. J. Language, Truth and Logic. New York: Dover Publication, 1952. . Logical Positivism. New York: The Free Press, 1959.

CARNAP, R. An Introduction to the Philosophy of Science. New York: Basic Books, Inc., 1966.

University Press, 1942.

Introduction To Semantics. Cambridge, Massachusetts: Harvard

. "Logical Foundations of the Unity of Science. In: International Encyclopedia of Unified Science. Chicago: University of Chicago Press, 1938. . "Intellectual Autobiography". In: SCHILPP, 1963a.

“O Caráter Metodológico dos Conceitos Teóricos”. In: Coleção Os Pensadores. São Paulo: Nova Cultural, 1975b [1956].

. “On Protocol Sentences”. In: Noús 21 (1987), p. 457-470. In: SARKAR, 1996 [1932c].

. "Replies and Systematic Exposition". In: SCHILPP, 1963, p. 8591013 [1963b].

"Testability and Meaning". In: Philosophy of Science, 3, p. 0140; 4, p. 420-471, 1936-7.

. The Unity of Science. Bristol: Thoemmes Press, 1932a.

The Logical Syntax of Language. New Jersey: Littlefield, Adams \& Company, 1934.

. The Logical Structure of the World. Berkeley e Los Angeles: University of California Press, 1928a. 
1949 [1936]. "Truth and Confirmation". In: FEIGL, H. and SELLARS, W. (eds.): Reading in Philosophical Analysis. New York, AppletonCentury-Crofts.

CIRERA, R. Carnap and the Vienna Circle: Empiricism and Logical Syntax. Amsterdam - Atlanta: Rodopi, 1994.

COFFA, J. A. The Semantic Tradition from Kant to Carnap. Cambridge: Cambridge University, 1995.

COHEN, R. S. and NEURATH, M. (eds.). Empiricism and Sociology. Boston: D. Reidel Publishing Company, 1973.

. "Dialectical Materialism and Carnap's Logical Empiricism". In: SCHILPP, 1963, p. 99-158.

FEIGL, H. "Physicalism, Unity of Science and the Foundations of Psychology”. In: SCHILPP, 1963.

FRIEDMAN, M. "The Re-Evaluation of Logical Positivism". In: Journal of Philosophy, vol. 88, p. 505-519, 1991.

1999.

. Reconsidering Logical Positivism. Cambridge: University Press, "Philosophy and the Exact Science: Logical Positivism as a Case Study”. In: EARMAN, 1992.

HAACK. S. Filosofia das Lógicas. São Paulo: Unesp, 1998.

LAKATOS, I. \& MUSGRAVE, A. (orgs). A Crítica e o Desenvolvimento do Conhecimento. São Paulo: Cultrix, 1979.

LAKATOS, I. "O Falseamento e a Metolologia dos Programas de Pesquisa Científica”. In: LAKATOS, 1979a.

LISTON, G. "Carnap e o Revisionismo”. In: Principia, 16(1), p. 99-119, 2012. NEURATH, O. "On The Psychology of Decision". In: NEURATH, 1983 [1973].

. "On The Classification of Systems of Hypotheses". In: NEURATH, 1983 [1916]. $1983[1930]$. "Ways of The Scientific World-Conception". In: NEURATH, NEURATH, 1983 [1931a]. .Physicalism". In: NEURATH, 1983 [1931b]. . "Empirical Sociology”. In: NEURATH, 1973 [1931c].

. "Sociology in The Framework of Physicalism". In: NEURATH, 1983 [1931d].

1983 [1934].

"Radical Physicalism and The 'Real World"'. In: NEURATH, .Pseudorationalism of Falsification. In: NEURATH, 1983 
[1935a].

“The Unity of Science as a Task". In: NEURATH, 1983 [1935b].

"Individual Science, Unified Science, Pseudorationalism". In:

NEURATH, 1983 [1936a].

.An International Encyclopedia of Unified Science". In:

NEURATH, 1983 [1936c].

."Encyclopedia as 'Model'”. In: NEURATH, 1983 [1936d].

.Physicalism and The Investigation of Knowledge". In:

NEURATH, 1983 [1936e].

."Unified Science and Its Encyclopedia”. In: NEURATH, 1983

[1937b].

.The New Encyclopedia of Scientific Empiricism". In:

NEURATH, 1983 [1937e].

.The Departmentalization of Unified Science". In: NEURATH, 1983 [1937/38a].

[1939/40].

"The Social Science and Unified Science". In: NEURATH, 1983

[1941].

"Universal Jargon and Terminology". In: NEURATH, 1983

"The Orchestration of Science by The Encyclopedism of Logical Empiricism”. In: NEURATH, 1983 [1946a].

. "Prediction and Induction". In: NEURATH, 1983 [1946b].

"Protocol Sentences". In.: AYER, 1959 [1959a].

"Sociology and Physicalism". In: AYER, 1959 [1959b].

"Physicalism". In: SARKAR, 1996 [1931].

"Unified Science as Encyclopedic Integration". In: International

Encyclopedia of Unified Science. Chicago: University of Chicago, 1938.

Empiricism And Sociology. Eds. by Robert S. Cohen \& Marie Neurath, (Vienna Circle Collection vol. 1). Dordrecht: Reidel, 1973.

. Philosophical Papers 1913-1946. Ed. and transl. by Robert S. Cohen \& Marie Neurath, (Vienna Circle Collection vol. 16). Dordrecht: Reidel, 1983.

OBERDAN, T. "Discussion: The Vienna Circle's 'Anti-Foundationalism'. In: Philosophy. Brit. J. Phil. Sci., 49, p. 297-308, 1998.

"Discussion: Deconstructing Protocols: Reply to Uebel". In:

Philosophy. Brit. J. Phil. Sci., 50, p. 301-304, 1999.

Editions Rodopi.

Protocols, Truth and Convention. Amsterdam - Atlanta:

POPPER, K. A Lógica da Pesquisa Científica. São Paulo: Cultrix, 1993. 
QUINE, W. V. “Dois Dogmas do Empirismo”. In: Coleção os Pensadores. São Paulo: Nova Cultural, 1985a.

. "Epistemologia Naturalizada". In: Coleção os Pensadores. São Paulo: Nova Cultural, 1985b.

RUSSELL, B. An Inquiry into Meaning and Truth. London and New york: Routledge, 1995 [1940].

RUTTE, H.“On Neurath's Empiricism and his Critique of Empiricism”. In: UEBEL, 1991.

SCHLICK, M. "O Fundamento do Conhecimento". In: Coleção Os Pensadores. São Paulo: Abril Cultural, 1988 [1934].

SCHILPP, P. A. (org.). The Philosophy of Rudolf Carnap. La Salle: Open Court, 1963.

STADLER, F. and NEMETH, E. (eds.). Encyclopedia and Utopia: The Life and Work of Otto Neurath (1882-1945). Dordrecht: Kluwer Academic Publishers, 1996.

UEBEL, T. Overcoming Logical Positivism From Within. Amsterdam Atlanta: Editions Rodopi B. V, 1992.

. (ed.). Rediscovering the Forgotten Vienna Circle. Austrian Studies on Otto Neurath and the Vienna Circle, (Boston Studies in the Philosophy of Science), Dordrecht: Kluwer, 1991. 